ORIGINAL ARTICLE

\title{
Cardiac involvement in HIV infected people in Yaounde, Cameroon
}

\author{
D Nzuobontane, K N Blackett, C Kuaban
}

Postgrad Med J 2002;78:678-681

See end of article for authors' affiliations

Correspondence to Dr Divine Nzuobontane Wirral Hospital Trust, St Catherine's Hospital, Birkenhead CH42 OLQ,

UK; divine.nzuobontane@ exchange.nwest.wirral-ha nhs.uk or

divinenz@hotmail.com

Submitted

19 December 2001

Accepted 29 May 2002

\begin{abstract}
Objective: To study the cardiac abnormalities in HIV infected patients in relation to the clinical stage of the disease and the immunological status of the patients.

Methods: A total 75 consecutive patients tested for HIV on the basis of clinical suspicion of the disease from July to September 1996 at the University Hospital Centre, Yaounde, Cameroon were recruited. The patients were classified into AIDS, HIV positive non-AIDS, and HIV negative according to clinical findings and outcome of ELISA and western blot testing. Every patient underwent a clinical examination, two dimensional and M-mode echocardiography, and blood lymphocyte typing.

Results: Dilated cardiomyopathy occurred in 7/30 (23.33\%) AIDS patients, 1/24 (4.17\%) HIV positive non-AIDS patient, but in none of the HIV negative patients. Other echocardiographic abnormalities included pericardial separation, effusion, thickening, and mitral valve prolapse. Although these abnormalities were more frequent in HIV infected patients, the differences did not reach levels of statistical significance. Dilated cardiomyopathy occurred in six $(31.58 \%)$ of the patients with a CD4 cell count $\leqslant 100 / \mathrm{mm}^{3}$ and two $(6.06 \%)$ in those with absolute CD4 counts $>100 / \mathrm{mm}^{3}\left(\chi^{2}=4.02, p=0.03\right)$. Conclusions: Cardiovascular abnormalities are frequent in African HIV infected patients but clinically discrete. Low CD4 cell counts are associated with dilated cardiomyopathy. These abnormalities should be expected with greater frequency in cardiological clinical practice as management of opportunistic infections improves in a situation of continued high disease prevalence in Africa.
\end{abstract}

$\mathrm{H}$ IV infection is the single greatest health challenge facing African countries today. In 1996 the prevalence of HIV in Cameroon was estimated at $4.3 \%$ in the general population. Today, it has almost tripled to $11 \%{ }^{12}$ There is very little doubt that these figures may be an underestimate of the real situation. The social and economic implications of the rising prevalence cannot be over-emphasised.

An increasing number of studies have documented HIV related cardiac disorders. HIV infection has been shown to be associated with endocardial, myocardial, and pericardial abnormalities. ${ }^{3-18}$ HIV associated myocarditis has been extensively studied with HIV virions detected in myocardial cells of HIV infected patients. ${ }^{8}$ Many studies have shown that HIV is an important cause of dilated cardiomyopathy. ${ }^{3-5} 815$ Other factors such as zudovidine cardiotoxicity and nutritional deficiencies are associated with dilated cardiomyopathy in HIV infected patients. ${ }^{671920}$ Pericardial disease is also an important feature of HIV associated heart disease. ${ }^{11-14}{ }^{16}$ Symptomless effusions have been found in up to $22 \%$ of AIDS patients. ${ }^{16}$ Infective endocarditis in HIV seems to be related to intravenous drug use. It occurs in $6.3 \%-34 \%$ of HIV infected intravenous drug users. ${ }^{17}$ Non-bacterial thrombotic endocarditis also occurs in HIV infected patients especially those with HIV wasting syndrome. ${ }^{17}$ There are increasing reports of coronary artery disease in HIV infected patients on highly active antiretroviral therapy (HAART). ${ }^{21-24}$ Coronary artery disease may be related to lipodystrophy, insulin resistance, and raised levels of low density lipoprotein cholesterol which complicate HAART. ${ }^{17}$ In Africa, where most of the people with HIV live, end organ manifestations of HIV have not attracted sufficient attention. The ever increasing prevalence of HIV infection in Africa coupled with improved management of opportunistic infections means that patients will live long enough to present with end organ manifestations of the HIV. This demands an awareness by clinicians of its cardiovascular manifestations for a complete and rational diagnosis and management. Even if the percentage of those developing car- diac complications is small, the cardiological disease burden could be substantial in the presence of very high prevalence of the infection in Africa.

Further, as avenues are explored for more access to HAART for African patients, clinicians in this part of the world should be prepared to recognise and manage end organ failures which will inevitably accompany improved survival.

\section{PATIENTS AND METHODS Study population}

In this cross sectional hospital based study, we recruited 75 consenting patients referred for HIV testing at the University Hospital Centre Yaounde, Cameroon, from July to September 1996, on the basis of clinical suspicion of HIV infection. The clinical symptoms relating to HIV infection which prompted referral for HIV tests included prolonged fever, weight loss, cough, and prolonged diarrhoea. One patient had disseminated Kaposi's sarcoma. Patients with a documented history of cardiovascular disease before the HIV test were excluded from the study. Fifty four patients were HIV positive and 21 HIV negative. Thirty of the HIV infected patients had clinical AIDS according to the World Health Organisation/Bangui clinical definition for AIDS in Africa. ${ }^{25}$

\section{Study procedures}

All patients underwent a thorough clinical assessment which enabled classification into three categories (AIDS, HIV positive non-AIDS, HIV negative) according to the clinical definition for Africa ${ }^{25}$ and the detection of cardiovascular disease.

Abbreviations: HAART, highly active antiretroviral therapy; LVEDD, left ventricular end diastolic diameter; LVEDV, left ventricular end diastolic volume; LVESD, left ventricular end systolic diameter; LVESV, left ventricular end systolic volume; LVFS, left ventricular fractional shortening 
Table 1 Echocardiographic measurements in the three patient groups; values are mean (SD)

\begin{tabular}{lcccc}
\hline & AIDS $(\mathrm{n}=30)$ & $\begin{array}{l}\text { HIV }(+) \text { non-AIDS } \\
(\mathrm{n}=24)\end{array}$ & HIV $(-)(\mathrm{n}=21)$ & $\begin{array}{c}\text { ANOVA } \\
(\mathrm{p} \text { value })\end{array}$ \\
\hline LVESD $(\mathrm{mm})$ & $30.40(7.89)$ & $30.25(5.76)$ & $25.57(4.93)$ & 0.039 \\
LVESV (ml) & $40.02(25.86)$ & $37.75(17.00)$ & $25.05(11.93)$ & 0.028 \\
LVEDD (mm) & $44.33(6.09)$ & $45.83(5.39)$ & $41.29(5.10)$ & 0.026 \\
LVEDV (ml) & $91.66(30.27)$ & $98.34(25.10)$ & $77.10(22.53)$ & 0.029 \\
LVEDD/BSA $\left(\mathrm{cm} / \mathrm{m}^{2}\right)$ & $3.01(0.47)$ & $2.90(0.33)$ & $2.70(0.33)$ & 0.025 \\
LVFS (\%) & $32.04(6.43)$ & $34.24(7.98)$ & $38.34(4.20)$ & 0.043 \\
\hline \multirow{2}{*}{ ANOVA, analysis of variance; BSA, body surface area. }
\end{tabular}

Venous blood was collected from HIV infected patients for lymphocyte typing; this was obtained automatically using a flow cytometer (Facscount Becton Dickinson). Every patient underwent two dimensional and M-mode echocardiography. This investigation was performed and read by the same cardiologist who was blinded to the HIV status of the patient.

Right ventricle, left ventricular end systolic diameter (LVESD), left ventricular end diastolic diameter (LVEDD), interventricular septum, left ventricular posterior wall, and corresponding ventricular volumes (LVESV, LVEDV) were measured.

Left ventricular systolic function was determined by the left ventricular fractional shortening (LVFS) computed from the basic measurements using appropriate formulas and corrected to the body surface area:

LVFS $=($ LVEDD-LVESD $) /$ LVEDD $\times 100$

Dilated cardiomyopathy was diagnosed using two criteria: diffuse hypokinesia as shown by LVFS $<28 \%$ and left ventricular dilatation, LVEDD/body surface area $\geqslant 3.2 \mathrm{~cm} / \mathrm{m}^{2}$.

\section{Statistical analysis}

Comparisons were done using $\chi^{2}$ analysis with Yates's continuity correction when necessary. Analysis of variance was performed for comparison of means of more than two groups and Student's $t$ test for comparison of two different groups. A value of $\mathrm{p}<0.05$ was considered statistically significant.

\section{RESULTS}

\section{Baseline patient characteristics}

Of the 75 patients, 54 were HIV positive and 21 HIV negative. Thirty of the HIV infected patients had AIDS according to the clinical definition for AIDS in Africa. ${ }^{25}$

Mean age and body mass index were not significantly different between the groups. The ages of the study subjects ranged between 19 years and 60 years; $87 \%$ of the HIV infected patients were aged between 26 and 45 years. Multiple heterosexual behaviour was the most common risk behaviour admitted by the HIV positive subjects (found in 59.3\%). None of the patients admitted to intravenous drug use.

\section{Clinical features with relevance to cardiac disease}

Cough $(53.7 \%)$, chest pain $(25.9 \%)$, and short of breath $(20.3 \%)$ were the most frequent clinical features with relevance to heart disease in the HIV infected patients. Most were non-specific, however, as many of the patients had concomitant pulmonary disease.

\section{Blood lymphocyte counts in HIV infected patients}

AIDS patients had a mean CD4 count of $119 / \mathrm{mm}^{3}$ and HIV positive non-AIDS patients $341 / \mathrm{mm}^{3}(\mathrm{p}<0.01)$; 19 of the 52 HIV infected patients who had blood lymphocyte typing had a CD4 count $\leqslant 100 / \mathrm{mm}^{3}$. Two HIV infected patients whose samples could not processed within four hours were excluded from any analysis involving CD4 cell counts.

\section{Echocardiographic measurements}

Left ventricular dimensions were generally higher in the HIV infected groups (table 1).

(A) Comparison of measurements in AIDS and HIV negative groups

- The mean values of LVES, LVESV, LVEDD, and LVEDV were significantly higher in AIDS group than the HIV negative group $(\mathrm{p}<0.05)$.

- The mean (SD) LVFS in AIDS patients was 32.04 (6.43) and HIV negative patients $38.34(4.20)(\mathrm{p}<0.05)$.

- The mean (SD) LVEDD/body surface area $\left(\mathrm{cm} / \mathrm{m}^{2}\right)$ was 3.01 (0.47) in AIDS patients and $2.70(0.33)$ in HIV negative patients $(\mathrm{p}<0.05)$.

(B) Comparison of measurements in HIV positive non-AIDS and HIV negative groups

- The mean values of LVEDD and LVEDV were significantly higher in the HIV positive non-AIDS group than in the HIV negative group $(\mathrm{p}<0.05)$.

- Although the LVFS was lower in HIV positive non-AIDS group, the difference between the two groups did not reach levels of statistical significance.

- HIV positive non-AIDS patients had a mean (SD) LVEDD/ body surface area $\left(\mathrm{cm} / \mathrm{m}^{2}\right)$ of $2.90(0.33)$ and HIV negative patients $2.70(0.33)(\mathrm{p}<0.05)$.

\section{Echocardiographic abnormalities}

Echocardiographic abnormalities were consistently more frequent in HIV infected (AIDS and HIV positive non-AIDS) groups than in the HIV negative group (see table 2 ).

Dilated cardiomyopathy occurred in $7 / 30$ (23.33\%) AIDS patients, 1/24 (4.17\%) HIV positive non-AIDS patients, but in none of the HIV negative patients. The difference was statistically significant when the AIDS group was compared with the HIV negative group $\left(\chi^{2}=3.88, \mathrm{p}<0.05\right)$.

Other echocardiographic abnormalities included pericardial seperation, effusion, thickening, and mitral valve prolapse. Although these abnormalities were more frequent in HIV

Table 2 Echocardiographic abnormalities by group; values are number (\%)

\begin{tabular}{llll}
\hline & $\begin{array}{l}\text { AIDS } \\
(\mathrm{n}=30)\end{array}$ & $\begin{array}{l}\text { HIV (+) } \\
\text { non-AIDS } \\
(\mathrm{n}=24)\end{array}$ & $\begin{array}{l}\text { HIV } \\
\text { negative } \\
(\mathrm{n}=21)\end{array}$ \\
\hline $\begin{array}{l}\text { Dilated cardiomyopathy } \\
\text { Pericardial disease }\end{array}$ & $7(23.0)$ & $1(4.17)$ & - \\
$\quad$ Systolic separation & $6(20.0)$ & $2(8.33)$ & $2(9.52)$ \\
$\quad$ Effusion & $6(20.0)$ & $2(8.33)$ & $1(4.76)$ \\
$\quad \begin{array}{l}\text { Pericardial thickening } \\
\text { Mitral valve prolapse }\end{array}$ & $3(10.0)$ & $3(12.50)$ & $2(9.52)$ \\
\hline
\end{tabular}


Table 3 Echocardiographic abnormalities in HIV infected patients with CD4 counts less than or over $100 / \mathrm{mm}^{3}$; values are number $(\%)$

\begin{tabular}{llll}
\hline & $\begin{array}{l}\text { CD4 } 5100 \\
(\mathrm{n}=19)\end{array}$ & $\begin{array}{l}\text { CD4 }>100 \\
(\mathbf{n}=33)\end{array}$ & $\mathrm{p}$ Value \\
\hline Dilated cardiomyopathy & $6(31.58)$ & $2(6.06)$ & $<0.05$ \\
Pericardial disease & & & \\
$\quad$ Systolic separation & $4(21.05)$ & $2(6.06)$ & $\mathrm{NS}$ \\
$\quad$ Effusion & $5(26.32)$ & $3(9.09)$ & $\mathrm{NS}$ \\
$\quad$ Thickening & $1(5.26)$ & $3(9.09)$ & $\mathrm{NS}$ \\
Mital valve prolapse & - & $1(3.03)$ & \\
\hline NS, not statistically significant. & & & \\
\hline
\end{tabular}

infected patients, the differences did not reach levels of statistical significance when the groups were compared $2 \times 2$.

Dilated cardiomyopathy occurred in $14.8 \%$ (8/54) HIV infected patients (AIDS and HIV positive, non-AIDS patients taken together) but in none of the HIV negative patients.

Patients with dilated cardiomyopathy had a mean CD4 count of $142 / \mathrm{mm}^{3}$ compared with $231 / \mathrm{mm}^{3}$ for those without dilated cardiomyopathy. There was no significant difference in the body mass index of patients with and without dilated cardiomyopathy. Dilated cardiomyopathy occurred in six $(31.58 \%)$ of the patients with a CD4 cell count $\leqslant 100 / \mathrm{mm}^{3}$ and two $(6.06 \%)$ in those with absolute CD4 counts $>100 / \mathrm{mm}^{3}$ $\left(\chi^{2}=4.023, \mathrm{p}<0.05\right.$; see table 3$)$. No significant difference was found in the frequency of other echocardiographic abnormalities between the groups, although abnormalities were consistently more frequent in the patients infected with HIV.

\section{DISCUSSION}

Cardiovascular manifestations of HIV infection have not attracted much attention in the African clinical setting; this is partly because the clinical picture of HIV infection is still dominated by opportunistic infections and malignancies. The findings of this study, for which data were collected a few years ago, are all too relevant today with the increasing prevalence of HIV and the hope of greater access to antiretroviral medications. More and more African patients may live long enough to present with end organ disorders.

We contemplated a case-control design, but the obvious difficulty in identifying an appropriate control group in our setting led to the adoption of the cross sectional design. Our HIV negative subjects were therefore not normal because they had an HIV test on the basis of clinical suspicion. The use of an HIV negative group with more than half of the patients chronically ill provided an advantage of having patients with similar baseline characteristics. Similarly, Himelman et al used patients with acute leukaemia as their control group while studying cardiac manifestations in HIV infection by two dimensional echocardiography. ${ }^{3}$

Although cough, short of breath, and chest pain (symptoms of heart disease) were considerable in our patients, their clinical implications must be taken with a degree of caution, as they could be attributable to pulmonary disorders. Patients with HIV infection are known to develop multiple pulmonary opportunistic infections, which were present in many of our patients. This obviously leads to problems of differential clinical diagnosis with cardiovascular disease. Only one of our patients (AIDS group) presented with the classical clinical picture of congestive heart failure with cough, dyspnoea, tender hepatomegaly, and oedema. Most of the patients were free of specific cardiovascular symptoms or signs. These findings show that cardiac abnormalities in African patients are clinically discrete. Even though we verified available medical records of all patients for evidence of previously documented heart disease, we cannot be certain as to the absence of pre-existing cardiovascular disease in the patients before HIV infection. In a system where access to health services is considerably limited by financial and other constraints, coupled with far from optimal medical record keeping, it is difficult to achieve a complete and up to date medical history for patients.

Our findings confirm that progressive left ventricular dilation accompanies disease progression in HIV infection. Left ventricular systolic dysfunction also shows a similar degradation as the disease progresses. Longo-Mbenza et al have also recently shown, in a study on African patients, that diastolic dysfunction that usually precedes systolic dysfunction is an important feature of HIV associated heart disease. ${ }^{26}$

Most HIV related cardiovascular abnormalities go undetected in the African clinical setting because the emphasis is still on managing opportunistic infections, because cardiac abnormalities are clinically discrete, and the lack of awareness by clinicians. There is little doubt that detection and appropriate management of cardiac abnormalities would improve the quality of life and survival of HIV infected people.

Dilated cardiomyopathy was predominantly an echocardiographic diagnosis in our series as only one patient with it had the clinical features of dilated cardiomyopathy. Our 14.8\% prevalence of dilated cardiomyopathy in HIV infected people is in agreement with that reported in previous studies."

Dilated cardiomyopathy, like other cardiac abnormalities in our series, had a tendency to occur in the late stages of the HIV disease spectrum; it occured mainly in the AIDS and HIV positive non-AIDS groups. The higher frequency of cardiac abnormalities in the patients with CD4 counts $\leqslant 100 / \mathrm{mm}^{3}$ indicates an association between the degree of immunosupression as made manifest by CD4 depletion in our patients. This association has been previously reported ${ }^{6}$ It is important to emphasise that other myocardial risk factors-for example, cardiotoxic antiretroviral medications and diabetes, were absent in our patients.

HIV virus itself aside, other causes of dilated cardiomyopathy in HIV infection may include factors ranging from nutritional, ${ }^{67}$ effects of other viral and parasitic infections (for example toxoplasmosis), ${ }^{8}{ }^{15}$ to antiretroviral medications. ${ }^{19} 20$ There is increasing interest in the role of selenium deficiency in HIV related heart disease. ${ }^{17}{ }^{18}$ Selenium deficiency as a cause of HIV related heart muscle disease may be of considerable interest in Africa. Patients often present with multiple nutritional deficiencies, prolonged diarrhoea, and wasting, which may involve selenium deficiency. While infectious, parasitic, and nutritional factors may be involved, the aetiology of HIV related dilated cardiomyopathy in Africa remains to be elucidated.

Previous studies have indicated that the prognosis and survival of patients with HIV related dilated cardiomyopathy is poor. $^{52728}$ It may be necessary in African patients to echocardiographically screen patients in the late stages of HIV infection with even mild symptoms of cardiac disease for cardiac abnormalities as these are often discrete.

The marked absence of endocardial involvement in our series may be related to the low prevalence of intravenous drug use in our patients. There was no evidence of intravenous drug use in any of the patients.

The spectrum of pericardial disease ranged from systolic seperation of the the pericardium, through pericardial thickening, to pericardial effusions. Most of the pericardial effusions were small and had not been suspected clinically apart from one patient with disseminated Kaposi's sarcoma who had a moderately large effusion.

This study was incapable of determining the precise aetiology of effusions as these were small and pericardiocentesis would have been difficult to undertake. In Africa, Mycobacterium tuberculosis infection is often incriminated, ${ }^{1429}$ however, pericardial fluid analysis is not always revealing. ${ }^{11}$

Even though pericardial abnormalities were more frequent in AIDS patients, we did not find a statistically significant difference in the frequency of the abnormalities between the 
patient groups. In contrast Moreno et al found that pericardial effusions were associated with advanced stages of the disease. ${ }^{12}$ The association might have been obscured in our study by the relatively smaller sample. Of considerable clinical significance is the fact most pericardial effusions in our series were not clinically suspected. The high prevalence of symptomless effusions is well documented..$^{15}$ In the African setting where large effusions related to $M$ tuberculosis are frequent, early diagnosis of effusions may avert the clinical consequences of pericardial tamponade.

Mitral valve prolapse was an echocardiographic finding in two HIV infected patients (3.7\%) but was found in none of the seronegative patients. The similar incidence of this abnormality in our HIV infected patients to that commonly reported in the general population, coupled with the absence of any significant difference between the groups, suggests that it was certainly a chance finding.

\section{CONCLUSION}

Heart involvement in HIV infection is common in African patients but still obscured by infections. Generally, manifestations are simillar to those reported in Western countries and are mainly related to heart muscle and pericardial involvement. With the improving treatment of opportunistic infections and the unabating prevalence of HIV infection in Africa, clinicians should be aware of the these abnormalities to ensure appriopriate, comprehensive, and rational patient care.

\section{Authors' affiliations}

D Nzuobontane, Wirral Hospital Trust, St Catherine's Hospital, Birkenhead, Merseyside, UK

K N Blackett, University Hospital Centre, Faculty of Medicine and Biomedical Sciences, Yaounde, Cameroon

C Kuaban, Faculty of Medicine and Biomedical Sciences, University of Yaounde 1, Cameroon

\section{REFERENCES}

1 UNAIDS. Epidemiological factsheets on HIV and sexually transmissible diseases, Cameroon. 2000 Update.

2 National AIDS Commission, Ministry of Public Health. AIDS control execution manual. Yaounde, January 2001.

3 Himelman R, Chung W, Chernoff N, et al. Cardiac manifestations of human immunodeficiency virus infection: a two dimensional echocardiography study. J Am Coll Cardiol 1989;13:1030-6.

4 Herskowitz A, Vlahov D, Willoughby S, et al. Prevalence and Incidence of left ventricular dysfunction in patients with human immunodeficiency virus infection. Am J Cardiol 1993;15:955-8.

5 Curie P, Ashok J, Foreman A, et al. Heart muscle disease related to HIV infection; prognostic implications. BM 1994;390:1605-7.
6 Chariot $\mathbf{P}$, Perchet $\mathrm{H}$, Monnet I. Dilated cardiomyopathy in HIV patients. N Engl J Med 1999;340:732-5

7 Hoffman M, Lipshultz S, Miller T. Malnutrition and cardiac abnormalities. HIV infected patients. Nutritional aspects of HIV infection. London: Arnold, 1999:33-9.

8 Barabaro G, LorenzoG, Grisorio B, et al. Incidence of dilated cardiomyopathy and detection of HIV in myocardial cells of HIVpositive patients. N Engl J Med 1998;339:1093-9.

9 Carr A, Cooper D. Adverse effects of antiretroviral therapy. Lancet 2000;356:1423-30.

10 Milei J, Grana D, Fernandez A, et al. Cardiac involvement in acquired immunodeficiency syndrome-a review to push action. The Committee for the Study of Cardiac Involvement in AIDS. Clin Cardiol 1998;21:465-72.

11 Silva-Cardos J, Moura B, Martins L, et al. Pericardial involvement in human immunodeficiency virus infection. Chest 1999:115:418-22.

12 Moreno R, Villacastin J, Bueno H, et al. Clinical and echocardigraphic findings in HIV patients with pericardial effusions. Cardiology 1997; 88:397-400.

13 Eisenberg M, Amy S, Schiller N. HIV associated pericardial effusions. Chest 1992:102:956-8.

14 Gegeilski J, Ramaaiya K, Lallinger G, et al. Pericardial disease and human immunodeficiency infection virus in Dar es Salaam, Tanzania. Lancet 1990;335:209-12.

15 Barbaro G. Cardivascular manifestations of HIV infection. J R Soc Med 2001;94:384-90.

16 Heidenreich PA, Eisenberg MU, Kee KL, et al. Pericardial effusions in AIDS. Incidence and survival. Circulation 1995:92:3229-34.

17 Rerkpattanapipat P, Wongpraprut N, Jacobs L, et al. Cardiac manifestations of acquired immunodeficiecy syndrome. Arch Intern Med 2000;160:1542-8

18 Barbaro G, Di Lorenzo G, Grisorio B, et al. Cardiac involvement in acquired immunodeficiency syndrome. A multi-center clinical-pathological study. AIDS Res Hum Retroviruses 1998;14:827-38.

19 Herskowitz A, Wiloughby SB, Baghman K, et al. Cardiomyopathy associated with antiretroviral infection in patients with HIV infection: a report of six cases. Ann Intern Med 1992;116:311-13.

20 Domanski MJ, Sloas MM, Follman DA, et al. Effect of zudovidine and danosine treatment on heart function in children infected with human immunodeficiency virus. J Pediatr 1995;127:137-46.

21 Sullivan A, Nelson M, Moyle G, et al. Coronary artery disease occuring with protease inhibitor therapy. Int J STD AIDS 1998;9:711-12.

22 Henry K, Melrow H, Huesbsch J, et al. Severe coronary heart disease with protease inhibitors [letter]. Lancet 1998;351:1328.

23 Behrens G, Schmidt H, Meyer D, et al. Vascular complications associated with HIV protease inhibitors [letter]. Lancet 1998;351:1958.

24 Flynn T, Bricker L. Myocardial infarction in HIV infected men receiving protease inhibitors [letter]. Ann Intern Med 1999;131:548.

25 World Health Organisation. AIDS in Africa. A manual for physicians. Geneva: WHO, 1992.

26 Longo-Mbenza B, Seghers L, Vita E, et al. Assessment of ventricular diastolic function in AIDS patients from Congo: a Doppler echocardiographic study. Heart 1998;80:184-9.

27 Lipshultz S. Dilated cardiomyopathy in HIV infected patiens [editorial] NEngl J Med 1998;339:1153-5.

28 Lipshultz S, Easley D, Orav E, et al. Cardiac dysfunction and mortality in HIV infected children. The prospective P2C2 HIV multicenter Study. Circulation 2000;102:1542-8.

29 Longo-Mbenza B, Tonduangu K, Seghers K, et al. HIV infection and pericardial disease invasion in Africa. Arch Mal Coeur Vaiss $1997: 90: 1377-84$ 